\title{
(Ir)racionalidade Médica: Os Paradoxos da Clínica*
}

KENNETH ROCHEL DE CAMARGO JR.**

\section{Introdução}

Este estudo assume como ponto de partida a produção teórica que delineou uma visão crítica da prática médica e de suas relações com a sociedade, um tanto esquematicamente dividida em duas vertentes principais: uma lidando com aspectos referentes ao que se convencionou chamar medicalização ${ }^{1}$ e outra ligada às relações com o complexo médico-industrial. ${ }^{2}$ Estas análises têm em comum a abordagem da medicina do ponto de vista do que poderíamos chamar de sua "externalidade". Complementarmente às mesmas torna-se necessário elucidar algo do que se dá internamente à própria prática e saber médicos, que permitem seu afastamento do que seria a sua finalidade precípua (ou pelo menos aquela que o establishment médico assume como tal), qual seja, curar e aliviar

* Este artigo é uma condensação da dissertação homônima, aprovada em setembro de 1990 como requisito parcial para a obtenção do título de Mestre em Medicina Social (IMS/UERJ).

** Médico do Hospital Universitário Pedro Ernesto/UERJ Mestre em Medicina Social (IMS/UERJ) Doutorando em Saúde Coletiva (IMS/UERJ)

1 P. ex., MACHA[XO, Roberto. et al., I anação da norma. Graal, Rio de Janeiro, 1984 e COSTA, Jurandir F., "A medicina das cidades", in Ordem médiéa e norma familiar. Graal, Rio de Janeiro, 1983.

2 P. ex., CORIDEIRO, Hésio A., A indústria da saúde no Brasil. Graal. Rio de Janeirn, 1980 
o sofrimento, para se transformar em instrumento de dominação e fonte de acumulação de capital.

\section{Seria a medicina uma ciência?}

Para responder a esta pergunta necessito, em primeiro lugar, explicitar seus dois conceitos fundamentais, quais sejam, o de ciência e o de medicina. Como a definição do conceito de ciência é, por si só, objeto de intensa polêmica, para dizer-se o mínimo, e uma discussão ampla desse aspecto desviaria o propósito deste trabalho, adotarei daqui por diante a definição das características fundamentais da racionalidade científica moderna e das disciplinas que a compõem. Assim, segundo Madel Luz, ${ }^{3}$ a racionalidade científica se caracteriza basicamente por ser um modo de produção de verdades mutávcis, a partir da aplicação de um

método alçado à categoria de doxa, por sua imutabilidade, e que pressupõe a formulação de enunciados lógicos, preferencialmente em linguagem matemática. Esse método e seus enunciados pretendem elucidar os mecanismos mais recônditos e as "leis naturais" que regem o Universo, do micro ao macrocosmo. Outra característica importante dessa racionalidade é a subdivisão, praticamente ao infinito, em disciplinas, isto é, domínios de enunciados científicos num campo específico de construção de objetos de discurso. ${ }^{4}$

A categoria medicina, por sua vez, também apresenta algumasdificuldades do ponto de vista conceitual. Em primeiro lugar porque "medicina" se refere tanto à prática quanto ao saber médicos; em segundo, porque não constitui, em nenhum momento, o bloco conceitual monolítico que supõe ser. Sob o título"medicina" abrigam-se uma técnica de prospecção de queixas (anamnese), outra de esquadrinhamento de sinais (semiologia) e um inventário de categorias diagnósticas - - "doenças" - e de seu tratamento (clínica), ${ }^{5}$ tratamentoentendido como um conjunto de estratégias de aniquilamento destas "doenças", usualmente baseado no uso de medicamentos e/ou cirurgias. Estes

3 LUZ, Madel T., Natural, racional, social. IFICS/UFRJ, Rio de Janeiro, 1987 (tese para provimento do cargo de professor titular).

44 LUZ, Madel T., ihid., especialmente o capítulo I: "A construção da racionalidade científica".

5 O próprio termo clínica é ambíguo, ora utilizado em referência à experiência médica como um todo, ora ao que chamo neste trabalho de "teoria das doenças". Lendo-se qualquer manual de clínica, vê-se que sua unidade básica é a doença, começando por sua descrição (sinais e sintomas, características laboratoriais e epidemiológicas) e encerrando-se com o tratamento (medicamentoso, em narticular) aderuadn 
três pilares assentam-se (do ponto de vista da formalização teórica) em disciplinas múltiplas, algumas especificamente ligadas à atividade médica (como a físiologia e a anatomia patológica), e outras de conexão mais remota (biologia, química). Uma outra disciplina fundamental para a medicina é a epidemiologia, que se apóia cada vez mais na matemática.

Esse conjunto desigual também se subdivide, por sua vez, num número crescente de ramos (especialidades), progressivamente mais restritos e pulverizados.

O suporte comum dessas facetas é, por um lado, uma prática (à qual voltarei adiante) e, por outro, um grupo de representações que emprestam coerência a esse mosaico. ${ }^{6}$ A dificuldade com esse grupo de representaçõos é que ele não se encontra explicitado em nenhum lugar, embora seja ubíquo. Pode-se percebê-lo claramente nas entrelinhas do saber médico; pode-se entrevê-lo quando um professor de medicina ensina. Num certo sentido, pode-se dizer que constitui a espinha dorsal da "ciência médica".

Esse grupo de representações poderia ser resumido em um número bem pequeno de proposições, tais como: "as doenças são coisas, de existência concreta, fixa e imutável, de lugar para lugar e de pessoa para pessoa; as doenças se expressam por um conjunto de sinais e sintomas, que são manifestações de lesões, que devem ser buscadas por sua vez no âmago do organismo e corrigidas por algum tipo de intervenção concreta." ${ }^{, 7}$ Estas proposições, que formam uma espécie de "teoria das doenças", não se encontram em lugar nenhum, mas dificilmente soariam estranhas a qualquer médico. Não sendo explicitadas, não podem ser confrontadas, dissecadas. Não sendo discutidas, impregnam cada palmo da atividade médica, sem se submeter aos cânones do dogma científico. Tais representações transformam-se numa espécie de "corpo teórico" paracientífico, com um conjunto de categorias próprias.

Os objetos precípuos da medicina, por sua vez, são historicamente excluídos do escopo do seu discurso. Categorias fundamentais, como sofrimento, saúde, homem, vida, cura encontram-se perdidas nas brumas do imaginário, ou empurradas para o terreno da metafísica. Mesmo o conceito de doença não é explicitado uma única vez, como demonstra Canguilhem, ${ }^{8}$ existindo apenas em oposição ao de saúde, que tampouco é definido.

Se as disciplinas que a constituem e/ou alimentam (as chamadas "especialidades médicas" e "disciplinas básicas", respectivamente) podem manter

6 Ou buscam emprestar, com sucesso relativo.

7 Por concreta entenda-se: remédio ou cirurgia.

8 CANGUILHEM, George. O nomal e o patológico. Forense-Universitária. Rin, 1982 
uma certa coerência interna e atender aos requisitos do método científico, o mesmo não se pode dizer da medicina, curiosa disciplina que ignora os conceitos fundamentais de seu próprio funcionamento. Um exemplo claro desta situação pode ser encontrado na discussão que Canguilhem ${ }^{9}$ faz a respeito da relação entre clínica e fisiologia experimental. Toda a experimentação fisiologica é, a princípio, rigorosamente enquadrada nos cânones da pesquisa científica. Isto não implica, por outro lado, que se possa ter uma definiçăo fisiologicista, "científica", do que venha a ser saudável ou patológico. Como lembra Canguilhem, o fisiologista já desenha sua investigação com uma definição prévia de que al go é expressão de doença, definição esla dada pela clínica. Além disso, dificilmente as observações de laboratório podem ser transpostas diretamente para situações reais, na medida em que um laboratório é algo bastante diverso de um ambiente "normal". Apesar disto, o trabalho se faz usualmente (inclusive em termos curriculares, já que o "normal" é ensinado primeiro, chegando-se depois ao "patológico") transcrevendo-se diretamente as normas laboratoriais para as situações clínicas. Assim, se a obtenção das chamadas "constantes fisiológicas" pode ser um ato da mais pura "ciência", sua utilização clínica certamente não é.

É este feixe algo caótico de fragmentos de discurso científico, carente de organicidade, que serve de suporte a uma prática historicamente intolerante com suas concorrentes, às quais acusa de "não científicas", como se ela própria o fosse. E é, ela mesma, um emaranhado igualmente desarticulado, no qual se misturam várias peças dissimétricas, que incluem em proporções variadas tradição, ciência, pressão das indústrias farmacêutica e de equipamentos e uma larga margem de incerteza.

O que pretendo aqui é pôr a nu tanto essa desarticulação metodológica quanto o enraizamento ideológico, que a meu ver dão sustentação à prática médica hoje hegemônica. Não basta apenas buscar raízes históricas (embora isso seja extremamente útil) para alcançar essa elucidação. Torna-se imperativo examinar o próprio ato médico na sua forma atual, tomado aqui como expressão concreta de uma enorme gama de determinaçôes, que vão desde o econômico até o psicológico. Sem querer negar importância a qualquer destas dimensões, dou prioridade aqui ao evidenciamento de três aspectos elementares desse ato: a busca pela atenção médica (como estratégia, socialmente aprendida, de eliminação ou controle de um sofrimento), a prática médica (entendida como procedimento padronizado de um corpo de especialistas) e o saber que a informa.

9 Op. cit., Parte I, cap. V. 


\section{Saber e prática médica e a busca pela saúde}

Existe algo que poderíamos chamar de mito constitutivo da medicina moderna, que vê a si própria como uma longa e triunfante batalha da Razão contra o Mal, representado pela doença, pela morte e também pela ignorância. Dentro deste mito, saber e prática médica formam um todo indissolúvel e harmônico, que tem como contrapartida a busca, individual ou coletiva, de uma ajuda especializada no combate a este Mal. Indissolúvel e harmônico porque interdependente; mais que isso, a busca cria a prática, e esta o saber. O último fundamenta a prática, que por seu turno atende às razões da busca. Fecha-se assim o ciclo. ${ }^{10}$

Isto não é, entretanto, o que ocorre. O conhecimento médico, originário da clínica, isto é, da prática à beira do leito, migrou para os laboratórios, e médicos e pesquisadores parecem ter se esquecido suas origens: “(...) Assim, enquanto na ordem didática, o patológico é deduzido do normal, na ordem heurística, ao contrário, é o normal que se estabelece a partir do patológico. Não se leva em conta essa inversão das coisas no ensino, e quando o fato é abundantemente demonstrado por Canguilhem, ${ }^{11}$ isto não muda nada nem no ensino da medicina, nem na sua prática." 12

A embrionária medicina científica moderna sofreu uma verdadeira revolução nos seus albores (séculos XVII e XVIII), ${ }^{13}$ que iria transfigurá-la em definitivo a partir do momento em que incorpora um novo equipamento - $\mathrm{o}$ hospital - e uma nova técnica, a necrópsia, base do método anátomo- clínico. ${ }^{14}$ Estes dois marcos determinaram a sustentação epistemológica do saber médico, que atravessou dois séculos inalterada.

Desde então, as doenças passam a ultrapassar os limites temporais (já que suas alterações deixam marcas indeléveis nos cadáveres) e espaciais (já que, com a lesão anatômica, a doença ganha uma essência que extrapola a mera experiência subjetiva do indivíduo) dos seus portadores. O que era antes um critério de agrupamento baseado em similitudes, uma taxonomia similar à de Linnaeus, passa a ter vida própria - torna-se doença. Mesmo as descobertas

10 FOUCAULT, Michel, O nascimento da clínica. Forense- Uiversitária, Rio de Janeiro, 1980. CLAVREUL, Jean, A ordem médica. Brasiliense, São Paulo, 1983.

11 E por Foucault também.

12 CLAVREUL, Jean, ibid.,pg. 53.

13 FOUCAULT, Michel, op. cit.; também: "O nascimento do hospital" in Microfísica do poder. Graal, Rio de Janeiro, 1981. ROSEN, George, Da polícia médica à medicina social. Graal, Rio de Janeiro, 1979.

14 FOUCAULT, Michel, op. cit. e ROSEN, George. on. rit 
de Pasteur e o advento da microbiologia — assim como uma série de façanhas espetaculares nos variados campos da biologia (genética, imunologia, bioquímica, etc.) e o novo aparelhamento tecnológico, conquistado em especial no pós-guerra - pouco alteram este modelo teórico, não representando nada que se aproxime da ruptura epistemológica do tipo que praticamente fundou a prática médica hegemônica nos nossos dias. ${ }^{15} \mathrm{Na}$ realidade, tais descobertas apenas aprofundam uma tendência previamente desenhada, levando-a às últimas consequiências. A verdade da doença deve ser buscada cada vez mais na intimidade microestrutural dos tecidos - principalmente nos tecidos mortos, porque os cadáveres não mentem. Assim, diagnosticar passa a ser uma tarefa a ser realizada apesar do doente, incontrolável fonte de erros, e o saber médico torna-se então um critério científico de exclusão, a maneira correta pela qual os doentes, estes ignorantes, deveriam se comportar. A ciência médica repete Procusto no seu afã de enquadrar, demarcar, disciplinar, normatizar. E ai daqueles que não respeitam a norma correta de adoecer! São os funcionais, os que não têm nada, os polissintomáticos, os pitiáticos - a eles, o castigo. Mesmo que este tipo de paciente responda por uma parcela considerável da demanda ambulatorial.

A própria relação entre saber e prática na medicina foge ao modelo harmonioso que a ideologia corporativa pressupõe. Não por desconhecimento - pelo contrário - mas por uma percepção nem sempre consciente, por parte dos médicos, da inadequação deste saber à realidade. As rotinas diagnósticas transformam-se numa conduta mecânica (e mecanizada) de localização de lesões - e de doenças, portanto - através do que já foi chamado de "eliminação através de exames apropriados". ${ }^{16}$ Os esquemas terapêuticos, largamente baseados no bulário e na propaganda da indústria farmacêutica, raramente vão além do método de ensaio-e-erro e/ou da prescrição de sintomáticos, incluídos aí um sem-número de psicofármacos mal empregados. Este saber, entretanto, persiste, principalmente como referencial ideológico, como já foi dito anteriormente, e como fonte de legitimação da prática de uns e exclusão da de outros: "charlatães" e "curandeiros". A "ciência médica" permanece como norma institucional (e como modelo ideal), e tudo que a contrariaé afastado, com apoio na ordem jurídica, inclusive. Assim, tudo que se refere à subjetividade, ao imaginário (por exemplo), é posto de lado como não científico, sendo objeto de uma "farmacologização" tão maciça quanto cega - sempre em nome da ciência.

15 FOUCAULT, Michel, op. cit. e ROSEN, George, op. cit.

16 BALINT, Michael. O médico, seu paciente e a doença. Atheneu. Rio de Janeiro, 1975. 


\section{Sofrer e saber: subjetividade vs. objetividade, ou o confronto clínico}

O "ponto de partida" da medicina, tanto historicamente quanto a cada nova consulta, é o sofrimento, como enfatizou Nélson Blank. ${ }^{17}$ Canguilhem e Foucault demonstram esta vinculação de forma inequívoca, o que não impede que na prática médica essa vinculação seja desconhecida permanentemente. A relação do sofrer com o saber é bastante paradoxal, em vários aspectos, como se pode ver a partir da leitura de Boltanski, Balint e Clavreul, entre outros.

Uma contradição fundamental se destaca para o propósito desta argumentação: para o paciente, a experiência da doença (sofrimento) é um fato concreto, incapacitante de uma forma que transcende sua capacidade de autocuidado, tornando necessária a intervenção do especialista. Para o médico, o sofrimento é irrelevante, e o paciente, fonte de distorções. Sua relação se dá com a doença, e o paciente é um mero canal de acesso a ela. Um canal muito ruim, por sinal, já que introduz "ruídos" em níveis insuportáveis. A idéia da "História Natural" das doenças esconde uma história de fabricação de objetos, sutilmente ocultada nos ensinamentos clínicos; ${ }^{18}$ pressupõe preexistência, descoberta, e não invenção. Isto é válido tanto do ponto de vista histórico- coletivo, na constituição do objeto da anátomo-clínica, quanto num corte transversal-individual, ao enquadrar-se aquele que sofre numa categoria diagnóstica. Assim, para o médico, a única realidade concreta é a da doença, expressão da lesão. O esquema referencial das doenças é, no entanto, mera classificação, artifício criado para enquadrar os fenômenos do processo saúde- doença. Ao esquecer isso, o médico passa a sobrevalorizar o artifício em detrimento do paciente, apagando seu sofrimento.

É interessante notar que o médico, apesar de procurar sempre se colocar no pólo objetivo desse confronto, não está imune, ele mesmo, às contradições da subjetividade, uma vez que seu raciocínio está sujeito ao crivo de sua experiência, instância de ressituação do conhecimento "objetivo" na sua práxis. ${ }^{19}$

Uma das contradições básicas da prática médica, tal como a conhecemos, pode ser expressa da seguinte forma: a "doença do médico" não corresponde à do paciente. Avançando um pouco mais nessa contradição, percebemos um

17 BLANK, Nélson. O raciocínio clínico e os equipamentos médicos. IMS/UERJ, Rio de Janeiro, 1985 (dissertação de mestrado) - p. 11.

18 FOUCAULT, Michel. ops. cits. RODRIGUES, Ricardo D., A crise da medicina: prática e saber. IMS/UERJ, Rio de Janeiro, 1979 (dissertação de mestrado).

19 BLANK, Nélson, op. cit., p. 49. 
desdobramento da mesma: a doença, enquanto categoria reificada, representa um tipo ideal (no sentido weberiano do termo), portanto genérico. O paciente é, por definição, indivíduo, e por isso sujeito a uma variabilidade infinita. Assim, enquanto o saber médico discursa sobre o coletivo, atua concretamente sobre o individual. A lacuna entre estes dois universos é preenchida pela experiência, o que implica de antemão a exclusão do método. O momento mesmo de coleta de dados, na anamnese e exame físico, implica a consideração de certos dados e exclusão de outros. A própria forma de interrogar o paciente pode induzir sintomas (e muitas vezes o faz), em especial no trecho conhecido por revisão de sistemas, quando o paciente é interrogado sobre a existência ou não de sintomas específicos da suspeita diagnóstica do médico. O critério para aproveitamento ou não de certos dados é dado pela própria sistematização clínica, o que leva a uma tautologia perigosa: o médico passa a procurar no paciente a doença que, de antemão, já pressentia.

\section{A teoria das doenças}

O eixo principal da "teoria da medicina" é, claramente, a teoria das doenças. Todo o trabalho médico está voltado para a identificação e eliminação, quando possível, das doenças e das lesões que as causam. Tudo o mais é secundário, inclusive o indivíduo que, incidentalmente, traz a doença: "(...) O saber médico é um saber sobre a doença, não sobre o homem, o qual só interessa ao médico enquanto terreno onde a doença evolui. (...) Mas o lugar onde o objeto subsiste não é o objeto. Para poder constituir a doença como objeto de estudo foi preciso entificá-la, constituí-la como um ser, reconhecível em suas manifestações 'semelhantes" de um doente a outro."20

Vê-se que, como já foi dito antes, a construção das doenças como categorias teve que ser feita excluindo-se os indivíduos acometidos; esta exclusão repete-se a cada instante na elaboração do diagnóstico das pessoas que buscam auxílio médico.

As categorias diagnósticas pressupõem um conjunto característico de sinais e sintomas que as definem; assim, todo livro-texto traz uma relação, por vezes extensa, do chamado "quadro clínico" de cada doença descrita. O problema é que esta relação inclui os dados possivelmente observados, o que năo quer dizer que um đado paciente vá apresentar todos eles, ou mesmo os considerados mais relevantes. As categorias clínicas são portanto abstrações,

20 CLAVREUL, Jean, op. cit., p. 121. 
agrupando uma infinidade de processos individuais; abstratas ao ponto de por vezes serem de difícil distinção entre si.

Para aperfeiçoar as descrições destas categorias, estudam-se as pessoas que estão enquadradas nelas, utilizando-se os métodos epidemiologicos (que serão discutidos adiante). Aí reside uma inconsistência fundamental: para elaborar-se a lista de sinais e sintomas da doença X, observa-se um grande número de casos de pacientes com a doença $X$. Ou seja, para obter-se a definição da doença $X$, o ponto de partida é a sua própria definição. Nessa tautologia repousa a elaboração e o aprimoramento das categorias diagnósticas.

Essa dificuldade metodológica também se encontra no momento em que se testa a capacidade de um determinado teste diagnóstico detectar uma disfunção ou doença: um novo teste é validado contra um antigo teste, o qual, por sua vez, tem também sua margem de erro. Mais ainda, a remissão última de toda e qualquer avaliação laboratorial é a definição clínica das doenças, embora no momento de solicitar um exame qualquer os médicos tendam atualmente a privilegiar seus resultados em detrimento da observação clínica, esquecendo que todo exame, por mais objetivos que sejam os dados que produz, está sujeito a um processo de interpretação.

Mesmo com a desvalorização da chamada "semiologia desarmada", o eixo central da racionalidade médica segue sendo a nosologia, que por sua vez está intimamente ligada à clínica. Desta forma, a incorporação dos resultados de exames laboratoriais ao processo clínico está sempre referido a uma interpretação, o que implica o recurso, uma vez mais, à experiência. Ou seja, por mais objetivos que sejam os dados de exames, sua utilização estará sempre sujeita à subjetividade do médico, que, por sua vez, é moldada pela teoria das doenças. Com isto queremos dizer que 0 ato de interpretar achados é determinado pela chave de interpretação, que, no caso do médico, é representada pelo arcabouço teórico da clínica.

A busca da "causa última" das doenças é basilar na medicina: a "essência" da doença reside em sua causa; logo, remova-se a causa e cessa a doença. Tanto é que o diagnóstico ideal, completo, é o etiológico, e a intervenção ideal é remover a causa. Doença e lesão estão umbilicalmente ligadas: uma não existe sem a outra. Esta montagem teórica é fundamental na construção do modelo médico de intervenção, pois a identificação produzida entre doença e lesão permite reduzir ao biológico todo o processo do adoecimento, excluindo componentes outros ("psicológicos", "sociais") que possam estar envolvidos nesta determinação. Mesmo a idéia de "multicausalidade" também se resume a uma série de causas igualadas entre si no concurso da produção da doença, que deságuam num mesmo estuário, a lesão, não sendo mais do que a unicau- 
salidade elevada a alguma potência, achatando perspectivas e apagando diferenças. Desta forma, a medicina ganha poder absoluto sobre a doença, na medida em que nada do que ocorre escapa aos seus domínios, já que, por definição, tudo acontece exclusivamente dentro deles. Isto não quer dizer que os médicos não reconheçam a concorrência de fatores extrabiológicos na produção da doença; estes são, entretanto, subjugados pelo referencial biológico. Um exemplo disso está na frase que ouvi de um interno de medicina, falando sobre o diagnóstico diferencial de distúrbios intestinais: "Mulher de meia idade, com dor em hipocôndrio direito, alterações de trânsito intestinal e pitiática é igual a cólon irritável." Ou seja, tudo aquilo que não é lesão está expresso nesta equação no termo "pitiática", termo pejorativo para se referir a pessoas com sofrimentos subjetivos. O subjetivo é aqui igualado aos outros componentes na produção do diagnóstico - que terá, provavelmente, como sequêencia lógica, a prescrição de um tranqüilizante, levando às últimas consequiências a biologização do sofrer subjetivo. Outro ponto a ser assinalado aqui é que, embora diagnóstico e terapêutica sejam etapas lógicas distintas, a construção de categorias diagnósticas traz implícito um projeto de intervenção, do qual não escapa o discurso preventivista, na medida em que está referido ao mesmo marco conceitual. $^{21}$ Poder-se-ia contra- argumentar que muitas vezes medicam-se pacientes que não têm diagnóstico. Há pelo menos dois pontos neste argumento que podem ser contestados: em primeiro lugar, "não ter um diagnóstico" pode ser discutível, já que muitas vezes o que se vê é que o médico não chegou a um diagnóstico definitivo, mas já dispõe pelo menos de um conjunto de hipóteses que fazem com que se sinta autorizado a agir. Mesmo no caso das "medicações sintomáticas", há algum tipo de diagnóstico presuntivo: se, por exemplo, prescrevo um analgésico para uma cefaléia, isto quer dizer que suponho que a mesma não se deve a qualquer causa orgânica que mereça maior investigação e tratamento. Ou seja, se é possivel prescindir-se de um diagnóstico formal, certamente o raciocínio clínico continua presente. Um tipo de situação que parece escapar a este raciocínio é o do paciente "não nosologisável", ou "refratário" como Eduardo Almeida o chama. 22

21 RODRIGUES, Ricardo D., op. cit.

22 "Assumindo a perspectiva de que o processo diagnóstico opera na realidade uma classificação, ou melhor, enquadre do indivíduo no discurso médico, denominarei os não-enquadrados de refratários." Almeida, Eduardo. Medicina hospitalar - medicina extra-hospitalar: duas medicinas? IMS/UERJ, Rio de Janeiro, 1988, (dissertação de mestrado) — p. 41. Pelo próprio recorte que este autor faz, o nome é bastante inapropriado. Para um médico, ao menos, isto soa como um paciente que não adere a um tratamento prescrito, por exemplo, e daí para o "paciente rebelde" a distância é mínima. Nesta lógica de pensamento, como é a 
Em primeiro lugar, é o caso de discutir-se se estes pacientes realmente não têm diagnóstico. Efetivamente os médicos costumam dizer que tais pacientes "não têm nada", querendo dizer que não há lesão. Afirmo, porém, que não enquadrar em nenhuma categoria diagnóstica conhecida, nesse caso, é também diagnóstico; é como se, ao final do compêndio de clínica ou do CID houvesse um item escrito "nenhuma das anteriores". Tanto é, que ao discorrer sobre as estratégias utilizadas pelos médicos para lidar com estes pacientes, 0 próprio autor identifica o que chama de "discurso da exclusão". 23

Não se trata, nesta situação, da formulação de qualquer diagnóstico psiquiátrico, mas sim de exclusão, pura e simples. E, neste caso, exclusão para uma área menos "nobre" da medicina, a Psiquiatria. Desta forma, o médico encontra uma "saída honrosa": não se pode dizer que ele tenha deixado o paciente à míngua, e ao mesmo tempo se livra dele. Os próprios pacientes devem perceher isto, na medida em que pudemos constatar que, no hospital onde trabalhamos, cerca de $50 \%$ dos encaminhamentos feitos por clínicos não se consumam, pois os pacientes sequer vão à Psiquiatria. ${ }^{24} \mathrm{Da}$ mesma forma que encaminha estes pacientes ao psiquiatra, o médico pode prescrever tranqüilizantes ou não fazer nada e simplesmente mandar o paciente embora, como aliás faz, por vezes. Com isto quero dizer que o simples fato de encaminhar alguém ao psiquiatra não quer dizer que se reconheça qualquer validade terapêutica na psiquiatria, e que qualquer forma de terapia, no sentido estrito, esteja sendo buscada nesse caso. Analogamente aos atos falhos, que revelam conteúdos inconscientes recalcados, estes pacientes, ao serem expulsos para a periferia do aparato médico expõem, pela omissão, a fragilidade da sustentação teórica da prática médica. Talvez por isso muitas vezes os médicos se tornem hostis a este tipo de paciente.

Tendo discutido possíveis objeções a esta proposição, reitero portanto a afirmação de que clínica e terapêutica são efetivamente indissolúveis. Evidência adicional pode ser vista no texto seguinte: “(...) Ora, a clínica não é uma

medicina que é refratária a eles, e não o contrário, penso que talvez o lógico fosse chamá-los de rechaçados.

23 "É mais um artifício médico do que propriamente um discurso com o corpo teórico e prática determinados. Consiste na aplicação da causalidade psíquica após o insucesso em revelar uma lesão/disfunção, ou agente etiológico (...) Se o caso não está inscrito na ordem somática é porque na realidade não pertence a esta ordem de discurso e sim a outra: a psíquica. (...) este discurso não elabora nem utiliza qualquer conhecimento da psicopatologia. Ele se resume em excluir o fenômeno da esfera somática e atribuí-lo à psíquica." Almeida, Eduardo, op. cit., p. 75 - grifo meu.

24 Por outro lado, ainda bem. 
ciência e jamais o será, mesmo que utilize meios cuja eficácia seja cada vez mais garantida cientificamente. A clínica é inseparável da terapêutica e a terapêutica é uma técnica de instauração ou de restauração do normal, cujo fim escapou à jurisdição do saber objetivo, pois é a satisfação subjetiva de saber que uma norma está instaurada." 25

Vê-se que não só existe uma ligação indissolúvel entre a classificação nosológica e o projeto de intervenção como também exatamente esta ligação introduz mais um elemento de indeterminaçã̃o na "ciência" médica.

Talvez por isso, a intervenção tenha um status menor em relação ao diagnóstico. Ou seja, uma vez definido o diagnóstico, a "ciência" pode sair de cena e dar lugar à "arte", já que daí em diante o caminho é "ladeira abaixo". A arte sobre a qual discorrem os teóricos da medicina revela-se então: trata-se de atividade subsidiária, a ser executada após o trabalho real ter se completado. Até porque o diagnóstico não pode ser confrontado, ao se obter um certo grau de certeza, uma vez que é um ato exclusivamente médico. Já a terapêutica implica necessariamente incertezas, possibilidade de fracasso, além de ser compartilhada, executada pelo paciente, no caso do ambulatório. O diagnóstico se faz até melhor com o paciente morto, e a terapêutica, obviamente, não.

$\mathrm{O}$ desinteresse dos professores pela terapêutica, citado por Eduardo Almeida, ${ }^{26}$ que $o$ atribui à divisão de trabalho entre a academia e a indústria farmacêutica, tem a meu ver outros determinantes. Em primeiro lugar, o trabalho "nobre" já foi feito ao se diagnosticar, e a partir do diagnóstico a terapêutica está determinada. Além disso, os professores não têm maiores compromissos com pacientes; seu grande momento é nas visitas (rounds) e nas sessões clínicas, oportunidades únicas de demonstrar todo seu saber.

No que diz respeito à pesquisa farmacêutica, efetivamente existem determinantes econômicos que não podem ser deixados de lado. A pesquisa de terapêutica por vezes até existe na academia, porém como caudatária da pesquisa industrial (nas economias periféricas; é possível que nas centrais as coisas se dêem de modo diverso). A lógica interna de funcionamento da medicina, por outro lado, não parece ser muito diversa nos dois lados do rio Grande. De qualquer modo, a indústria farmacêutica tem papel efetivo na determinação dos "esquemas terapêuticos" (assim como a de equipamentos, nos "esquemas diagnósticos"), que, todavia, não se esgota pura e simplesmente numa bem-sucedida estratégia de marketing, como lembra o próprio Eduardo Almeida. Parte do sucesso das estratégias da indústria, ao menos, deve ser

25 CANGUILHEM, Georges, op. cit., p. 185 - grifo meu. 26 Op. cit., p. 22-23. 
creditada ao proprio esquema conceitual que os médicos trazem consigo, os quais, entre outras coisas, reduzem a saúde/doença ao biológico, à presença ou não de lesão, e a terapêutica à administração de remédios segundo o bulário que os acompanha.

\section{O que a medicina pensa (e diz) sobre si própria}

Uma fonte essencial para a reflexão acerca do corpus teórico da medicina é dada pelos livros de referência adotados nas escolas médicas, em especial nos seus capítulos introdutórios, onde forçosamente alguma digressão geral acerca do saber e da prática estará presente. Além desta referência obrigatória, estas informações foram complementadas por um rastreamento de artigos publicados recentemente (1987-1989) em revistas médicas internacionais, abordando aspectos relativos à "ciência médica". Por razões de espaço, não apresento aqui as várias citações que conduzem a análise dos textos nem a relação completa da bibliografia consultada. Remeto o leitor interessado ao texto original da tese.

Fica claro, em primeiro lugar, na leitura desses textos, a admissão implícita de que nem tudo é ciência na medicina, disfarçada na menção ubíqua à arte da medicina. Não vou nem tentar discutir o que seria arte (já temos problemas suficientes com a reflexão sobre ciência...), mas o fato é que, ao mesmo tempo em que o saber reconhece sua limitação, tenta conferir à mesma um status diferenciado em relação a outras habilidades "comuns": se a prática é arte, então o médico é artista, e não artesão. ${ }^{27} \mathrm{Ou}$ seja, continua sendo algo muito especial.

A oposição estabelecida nesses textos entre quadro e conduta reforça minha argumentação: o saber (quadro) não é mais que uma referência genérica, pouco precisa, para a prática (conduta). Além disso, o primado fisiopatológico fica evidente na enunciação feita por Burke ${ }^{28}$ dos predicados fundamentais do médico: "técnico de saúde, conselheiro, amigo, confortador hábil e conhecedor da natureza humana". No que diz respeito à saúde, ${ }^{29}$ o médico é técnico. Já para as outras aptidões, a generalidade do "amigo" é suficiente. ${ }^{30}$

27 Arte aqui está claramente referida à "criação inspirada" e não à habilidade, à destreza e ao conhecimento eminentemente prático do artífice. A profissão médica, ainda que "artística" neste sentido, está firmemente subordinada a um saber cientifico.

28 BURKE, A., "O médico, o paciente e a doença", in Semiologia médica (Vieira Romeiro). Guanabara Koogan, Rio de janeiro, 1980.

29 Seja lá o que isso for. Nunca é demais assinalar que este termo tão fundamental nunca é definido, apesar de ser invocado várias vezes por este, bem como por outros autores.

30 Esta é uma divergência fundamental que tenho com a visão de Eduardo Almeida sobre uma presumida psicologização do que chama de "medicina extra-hospitalar" (op. cit.). Mesmo 
Note-se ainda que os dois termos da equação do ato médico - médico e paciente - só podem ser resolvidos à maneira da álgebra, igualando um dos termos a zero. O paciente só será fonte fidedigna de informação quando for completamente despersonalizado.

Mesmo quando se reconhece a importância de fatores externos ao modelo anátomo-clínico, não se lhes reconhece status científico; seriam componentes de uma "atitude", do "bom senso", numa espécie de regra de etiqueta que, embora bem-vinda, não é essencial. Ocorre então um movimento duplo de reconhecimento de que há situações (os "refratários" de Eduardo Almeida) que escapam ao saber médico, combinado com uma desqualificação de qualquer outra disciplina que possa vir a querer espaço na prática médica. Trata-se apenas de uma questão de experiência no exercício da "arte", que dispensa qualquer elaboração teórica, o que equivale, concretamente, a não reconhecer nesses pacientes o status de "doentes".

Voltando à já citada "arte da medicina", vê-se que esta é uma combinação de conhecimento médico, intuição e julgamento, características do médico hábil. Há uma aparente contradição com a ênfase na tecnicalidade da medicina. Mas, na verdade, podemos afirmar que o que este e outros textos semelhantes fazemé afirmar, docemente constrangidos, que medicina não é só ciência, senão mais que ciência, na medida em que exige, além do "sólido conhecimento" do cientista, as habilidades do artista (e não do artesão, como já foi dito anteriormente). Não nos iludamos, então; o primado absoluto, apesar dos acenos às musas da Arte, permanece sendo da "ciência", aqui representada pela anátomoclínica.

Falando de uma posição mais confortável, já que não tem que interagir diretamente com o paciente, o anátomo-patologista coloca as coisas no seu devido lugar de modo mais claro: "O médico iniciante ouve tantas vezes que deve preocupar-se com o paciente como um todo que chega a esquecer de que por trás de cada doença orgânica há células com mau funcionamento."32

Efetivamente o que observamos é que a preocupação com a "humanização" da medicina não ultrapassa o rol das boas intenções.

quando o saber médico reconhece a existência de algo que lhe escapa, relega-o para o terreno das "boas maneiras"... Os "modelos alternativos" para a Prática não chegam a se constituir em alternativa real para o modelo hegemônico.

31 V. observações anteriores sobre este assunto.

32 ROBBINS, S., Patologia estrutural e funcional. Interamericana, Rio de Janeiro, 1975. Acho que o autor exagera na sua preocupação. A médico nenhum, mesmo aos iniciantes, é dado esquecer que por trás da doença existe a lesão, e que isso é o que importa. 
Um outro aspecto que fica flagrante nesta breve excursão por primeiros capítulos é o que já suspeitávamos: o objeto da medicina nãoé nunca enunciado; no máximo, há referências a saúde e doença, mas, como Canguilhem demonstrou à exaustão, nenhum dos dois termos é definido, ambos são apenas contrapostos um ao outro.

Disso tudo ressalta que, ao tentar caracterizar a medicina como "ciência" e "arte", os teóricos (ideólogos?) acabam justificando um status supra (e não para) científico à medicina. Pois, se por um lado as ações de um médico são balizadas pela aplicação da ciência mais pura, este mesmo médico pode, quando assim lhe aprouver, deixar de lado as minúcias do método científico em prol de sua "arte".

É interessante, ainda, cotejar as regras determinadas nos manuais para se chegar ao diagnóstico com estudos que procuram determinar como, na prática, os médicos agem. Referência fundamental neste aspecto é um livro de epidemiologia clínica, ${ }^{33}$ em especial nos seus capítulos iniciais, sobre a elaboração de diagnósticos. A partir desta referência, registro dois aspectos fundamentais para a argumentação que aqui desenvolvo:

a) o método de trabalho preferencialmente utilizado na prática médica difere bastante do preconizado pela teoria, e nem por isso se mostra ineficaz;

b) a base do trabalho médico é a classificação dos pacientes nas categorias fornecidas pela teoria das doenças.

\section{Imaginário e cultural: pacientes e médicos}

Embora os aspectos imaginários da visão que os pacientes têm do seu processo mórbido sejam aparentemente mais evidentes, também costumamos hierarquizar as doenças de nossos pacientes, de acordo com nosso interesse acadêmico, entre outras coisas. Deste modo, doenças evidenciadas objetivamente são mais "graves" do que as ditas "funcionais", independentemente de qualquer consideração relativa ao sofrimento dos pacientes, que deveria, ao menos em tese, ser o referencial da prática médica. Quantos pacientes não foram classificados com a tristemente famosa condição de "não ter nada", simplesmente para negar-se-lhes qualquer ajuda?

Os médicos agem, de forma geral, como se as doenças fossem objetos concretos, esvaziados de qualquer significado, seja psíquico, seja cultural. Isto faz com que freqüentemente aquilo que o médico vê como problema seja

33 SACKETT, D. et al., Clinical epidemiology. Little, Brown \& Co. Boston, 1985. 
bastante diverso das preocupações do paciente. Não raro observamos, em nossa experiência com pacientes ambulatoriais em clínica médica, pessoas entrarem e saírem de consultas com a frustrante sensação de que nenhuma de suas "doenças" teve qualquer solução, e que o médico acrescentou algumas novas. Dito de outra forma, a doença depende tanto de quem tem quanto de quem diagnostica (ou de onde se diagnostica).

Determinadas reações que podem ser encontradas em qualquer manual de Psiquiatria como sintomas psicopatológicos podem ser parte integrante de rituais culturalmente estabelecidos - e não patologizáveis, portanto. ${ }^{34}$ Existem certas situações que despertam no médico respostas que dificilmente poderíamos qualificar de "cientificamente fundamentadas", em especial quando lida com o sofrimento não "nosologisável".

Da mesma forma que seus pacientes, um médico vê o mundo através do filtro de suas representações; só que o imaginário médico está sempre protegido pelo escudo da racionalidade científica. Existem concepções básicas comuns ao universo médico, alimentadas pelo processo de ensino-aprendizado, formal ou não, que não são, entretanto, "cientificamente" elaboradas. Desta forma, consolidam-se representações e modos de agir que passam através das gerações de médicos, muitas das quais francamente hostis aos pacientes que atendemos. Crenças também se solidificam desse modo, mesmo sem base empírica. Por exemplo, exames complementares que gerem uma imagem ou um valor numérico são mais prontamente aceitos pelos médicos como expressão da "verdade", mesmo que não haja qualquer razão científica para isso.

É interessante notar que não existe justificativa outra para a adoção das "rotinas laboratoriais" que não seja a experiência. Esta, no entanto, é enganosa; ao estudar possíveis benefícios trazidos pela realização rotineira de telerradiografias de tórax como método de screening (um dos componentes da "rotina" supracitada), Guimarães conclui que apenas em uma pequena proporção este procedimento resultou em benefício real para o paciente. ${ }^{35}$

O discurso médico é apenas mais um dos discursos sobre a doença/saúde, aquele que os médicos gostam de acreditar como "científico", "verdadeiro", mesmo que não seja exatamente assim. O que se observa é que, na verdade, o discurso médico acaba por ser uma forma bastante eficiente de manter o paciente alienado de sua própria situação. Uma das frases que mais ouvi,

34 GUEDES, S., "Umbanda e loucura". in VELHO, Gilberto (org.), Desvio e divergência. Zahar, Rio de Janeiro, 1979.

35 GUIMAR*ES, Reinaldo F.N., "A eficácia do exame telerradiográfico de tórax como técnica de screening hospitalar”. Rev. Saúde Públ., 11:97-109, 1977. 
tentando justificar o não-esclarecimento de pacientes sobre o que o médico pensa e pretende fazer é: "não adianta explicar nada para estas pessoas, são ignorantes" (e suas variações). O que efetivamente ocorre é que situações que poderiam ser entendidas são expostas num jargão ininteligível — a não ser para quem já é um iniciado. Pude ver num posto de vacinação contra meningite cartazes com advertências a pais e mães que vacinavam seus filhos, nos seguintes termos: "Se seu filho apresentar petéquias, exantema, equimoses, procure um posto de saúde". Quantas pessoas não médicas, mesmo com excelente nível de instrução, podem decifrar esta lista de sinais? Esta é uma das razões, independentemente de qualquer eficácia terapêutica, da preferência de determinados setores populacionais pelos curandeiros: eles, pelo menos, explicam o que as pessoas sentem em termos que elas podem entender, porque ambos, curandeiro e paciente, fazem parte de um mesmo recorte social. Por outro lado, esta explicação é, em si, terapêutica. ${ }^{36}$

\section{Fundamentação do saber. Epidemiologia e estatística}

Apesar de até certo ponto confinada aos "guetos" da saúde pública, ${ }^{37}$ a epidemiologia é essencial na construção dos objetos utilizados pelo saber e pela prática médica. Como já foi referido anteriormente, muito do que se lê nos manuais didáticos de clínica, tanto no que diz respeito às características de uma dada doença (sinais, sintomas e quadro laboratorial) bem como às formas adequadas de terapêutica, é validado e/ou sugerido por algum tipo de investigação epidemiológica, embora via de regra os médicos desconheçam esta origem. Um exemplo deste desconhecimento está na já citada supervalorização que os médicos fazem dos exames complementares: avaliados a partir de parâmetros epidemiologicamente determinados - sensibilidade e especificidade - estão todos limitados pelo fato de que seu valor enquanto critério diagnóstico está mais condicionado, via de regra, à prevalência da "doença" que busca diagnosticar do que às suas qualidades intrínsecas, o que usualmente não é considerado na interpretação de seus resultados.

A epidemiologia é chave para a validação dos conhecimentos relativos à teoria das doenças, que em última instância fundamentam qualquer intervenção

36 LÉVI-STRAUSS, Claude. "O feiticeiro e sua magia" "Eficácia simbólica". inAntropologia estrutural. Tempo brasileiro, Rio de Janeiro, 1975. Loyolla, Maria Andréa. Médicos e curandeiros. Difel, São Paulo, 1984.

37 Embora a epidemiologia clínica tente uma aproximação com a área clínica (como o próprio nome indica), em nosso meio sua penetração na área médica é bastante restrita. 
médica. Ela própria, porém, coloca-se como caudatária das construções clínicas, porque a evidência direta das relações que a investigação epidemiológica sugere sempre se dá no nível biológico, mesmo que isto faça persistir um (indesejável) grau de subjetividade. Naomar de Almeida Fo. afirma categoricamente que "a teoria da doença será sempre propriedade do discurso da Clínica, por mais que a Epidemiologia colabore para a sua construção." 38

Embora o autor lance mão desta afirmativa para afirmar a independência conceitual da epidemiologia, por outro lado autoriza a afirmação de que a epidemiologia é, num certo sentido, caudatária da clínica. ${ }^{39}$ Isto traz dificuldades adicionais. Como, neste caso, só se acha aquilo que se procura, a definição dos termos em estudo numa investigação molda, a priori, seu resultado futuro. Ou seja, ao se partir de uma definição mecânico-causal da doença, tudo o que se irá obter é uma inferência a respeito de uma relação causal, se válida ou não, excluindo-se automaticamente qualquer outra que não tenha sido explicitamente colocada no desenho do estudo. Exemplificando, se investigamos a relação entre a incidência da meningite tuberculosa e a cobertura vacinal, só obteremos evidências a respeito da possível relação do efeito-doença com a característica-vacina, e não de nenhuma outra (como, por exemplo, o estado nutricional, ou a inserção das pessoas estudadas no modo de produção).

Eduardo Faerstein demonstra o peso que concepções extra-científicas têm na determinação das hipóteses sobre fatores de risco que orientararão o desenho de estudos epidemiológicos (no caso, comportamento sexual como determinante para o câncer ginecologico). ${ }^{40} \mathrm{~A}$ influência da normatização médica é particularmente deletéria aqui, porque determina a própria criação das "evidências científicas" que legitimarão intervenções sociais em ampla escala, como exemplifica esse autor ao discutir as condutas estabelecidas para o tratamento cirúrgico do câncer de mama. Apesar de alternativas menos mutiladoras, comprovadamente eficazes, estarem disponíveis há anos, médicos e radioterapeutas continuam preferindo a mastectomia radical, em função do papel "subalterno" desempenhado pelas mulheres na sociedade. ${ }^{41}$

38 ALMEIDA Fo., Naomar, Epidemiologia sem números. Campus, Rio de Janeiro, 1989.

39 Para tentar minorar esta interferência, Sackett troca o termo doença por "desordem-alvo". (Sackett et al., op. cit.)

40 FAERSTEIN, Eduardo. "Ideologia, normas médicas e racionalidade epidemiológica: o caso do câncer genital feminino". Cad. IMS 3(1):173-86, 1989.

41 FAERSTEIN, Eduardo, op. cit., p. 179-180. Considere-se ainda o fato de que determinados ramos da medicina ainda são território predominantemente masculino. 
A estatística, por sua vez, representou uma importante ruptura epistemológica para a epidemiologia, uma vez que permitiu a passagem da descrição das epidemias (razão etimológica da própria denominação da disciplina) para a análise das causas do adoecimento. Ocorre que o método estatístico é pouco compreendido, em especial nas suas implicações como apoio para a produção de inferências. Este relativo desconhecimento, ${ }^{42}$ cntretanto, (talvez por isto mesmo) não impede que o "fato estatístico" seja bastante respeitado.

Existem, portanto, algumas questões melodológicas com relação à utilização da estatística que devem ser ahordadas. A primeira diz respeito ao caráter realmente aleatório da composição de amostras. base de toda a teoria da estimação estatística. Para se extrapolar conclusões de uma amostra para sua população de origem, é necessário um grau apropriado de certeza de que tal amostra é representativa da população em estudo. Isto é. via de regra, hastante difícil de ser garantido, especialmente se levarmos em conta a segunda dificuldade: como o intervalo de confiança para estimação de parâmetros populacionais a partir de medidas amostrais é inversamente proporcional à raiz quadrada do tamanho da amostra, para poder se estimar pequenas diferenças de risco torna-se necessário compor amostras muito grandes. Ocorre yue o aumento no risco populacional para um determinado fator entre os vários considerados na determinação das doenças crônico-degenerativas (usualmente abordadas a partir do referencial da "multicausalidade") é precisamente dessa ordem, e montar um estudo longitudinal com amostras desta magnitude é bastante difícil - c raramente feito. Recorre-se usualmente a estudos do tipo "caso-controle" em que um grupo de indivíduos doentes é comparado com outro de sadios. Nestes estudos é difícil evitar a incidência de vieses, tanto na amostra "doente" quanto na "sadia". 43 Outro aspecto relevante é a necessidade de ajuste da significância de cada teste, nas situações em que uma mesma amostrá é testada várias vezes. Isto está se tornando progressivamente mais importante com a existência de programas de computador que permitem retestar uma amostra por vários métodos e com diversos critérios, até que um teste dê resultado significativo; o mais grave é que é usualmente muito mais fácil operar um destes

42 Como se depreende do fato. citado em mas de um dos ar ligos consultados, de que 40 a $50 \%$ dos artigos de publicações médicas que empregam a estatístıca o fazem croneamente, sem que isto seja percebido por editores ou leitores.

43 Para uma discussão dos problemas metodológicos dos estudos caso-controle, ver Feinstein. Alvan et. al.. "Café e câncer de pâncreas: problemas da etiologia e pesquisa epidemiológica de caso-controle". Tradução de Meneghel. S. s/data (mimeo) Original publicado no JAMA. 246(9):957-61, 1981. 
programas e utilizá-lo para produzir "resultados", do que entender o que estes realmente significam.

Este tipo de discussão metodológica não é, via de regra, considerada pela maior parte dos médicos. Sem bagagem de conhecimentos adequada para poder interpretar criticamente dados estatísticos, eles tomam a "matematização" do real como critério de "verdade". Pouco importa se estamos lidando com um nível de abstração crescente, que nos aparta cada vez mais dos termos concretos do sofrimento, e, acima de tudo, incapaz de dar, por si só, a medida pela qual um achado deve ou não ser valorizado.

A crítica à busca da "evidência objetiva", em especial àquela advinda da utilização mágica da estatística, evidencia a maneira muito peculiar com que os médicos se apropriam da informação aportada pelo método experimental, transformando inferências em "verdades". Mais que isso, na transposição acrítica da situação experimental para a prática clínica. Sob a capa da "cientificidade", encontramos a reverência dogmática pelo saber. Dito de outro modo, a própria concepção que a medicina tem do que seja ciência é peculiar, atinente mais aos domínios da fé do que da pesquisa científica propriamente dita. Muito dessa atitude tem a ver, como seria de se esperar, com o proprio aparelho educacional.

A falta de uma "atitude científica" começa muito cedo nos bancos escolares, onde os conhecimentos científicos são ministrados a partir de uma visão ahistórica. No caso dos médicos, ainda há outro aspecto a ser considerado: o chamado "currículo paralelo", tão relevante no aprendizado quanto a escola formal.

Da discussão precedente emerge um quadro no qual duas disciplinas, epidemiologia e clínica, mantêm uma curiosa simbiose, onde uma depende da outra para a elaboração de seus objetos, ao mesmo tempo em que esta depêndencia é negada, pela "naturalização" destes mesmos objetos.

\section{Conclusões:}

\section{a. Clínica e ciências naturais}

Observando-se a relação da "teoria das doenças"44 com as várias disciplinas científicas que a informam evidencia-se uma operação que poderíamos

44 Destaco que ao longo deste tex to me referi sempre à "teoria das doenças" e não a uma "teoria da doença", porque esta última, como formulação geral. simplesmente inexiste. Fxistem 
chamar de "apagamento de rastros": a cuidadosa ocultação dos processos de produção do conhecimento. Vemos uma estratégia de "naturalização" de conceitos fundamentais, a começar pela própria definição das "doenças", referencial teórico básico da clínica. A maior evidência disto é o proprio nome escolhido por Leavell e Clark para seu modelo: "História natural das doenças". Esta relação é recíproca no que diz respeito a algumas disciplinas, em especial; como aponta Canguilhem, este é o caso da fisiologia, que depende da informação clínica prévia para distingüir "normal"/"não normal". Mas este é o caso também da epidemiologia, como parece sugerir Naomar de Almeida Fo.: para a epidemiologia, as "doenças" são dadas. Para a clínica, por sua vez, as informações aportadas pela fisiologia e pela epidemiologia também são dadas, naturais. Há claramente um esforço de situar o saber e a prática médica no interior do paradigma das ciências naturais. Isto fica mais claro a partir da reconstrução do processo clínico.

Como dissemos no início deste trabalho, a atividade clínica pode ser caracterizada pelos seguintes passos: anamnese, exame físico, diagnóstico/conduta. Implícito nesta seqüência está um processo de objetivação, de fazer surgir a partir da subjetividade do sofrimento do paciente a objetividade da doença, em passos graduais.

No momento da anamnese a subjetividade ainda está presente, porém desde já presa ao processo sistematizado de coleta que a aprisiona em caminhos de objetivação. Uma dor não é simplesmente uma dor; na anamnese médica, uma dor tem sede, intensidade, duração; tem características que a definem de modo inequívoco (é em facada, em pontada, ou tipo cólica, etc.). O passo lógico seguinte, o exame físico, praticamente silencia o sofrimento. Aqui, o paciente só existe enquanto "referência geográfica", como diz Clavreul.

Ao final desse processo, com o diagnóstico emerge, enfim, a doença, que tem como corolário um tratamento. Por mais que se diga, à exaustão, que "não existem doenças, e sim doentes", a prática médica demonstra o contrário: para a clínica é importante fazer desaparecer o subjetivo, para que surja a doença, e não o doente. A oposição subjetivo/objetivo corresponde outra, tão essencial à clínica quanto a primeira: a oposição particular/geral. Num certo sentido, talvez esta seja até mais importante do que a primeira, porque a construção de generalidades é que possibilita a acolhida da medicina no seio das "ciências naturais".

teorias sobre mecanismos fisiopatológicos, evidentemente, mas nada que sequer se assemelhe a uma "teoria geral do adoecer". A única construção teórica deste tipo é a discussão empreendida por Canguilhem. Mas esta continua excluída das referências da clínica. 
Porém, como demonstra Ginzburg, o paradigma da clínica é outro, aquele que denomina de "indiciário"; o primado da decodificação dos signos construindo individualidades. Segundo este autor, ao invés de operar sobre generalidades, este paradigma tem sentido justamente na individuação, feita a partir da leitura de sinais: "(...) Ora, é claro que o grupo de disciplinas que chamamos de indiciárias (incluída a medicina) não entra absolutamente nos critérios de cientificidade deduzíveis do paradigma galileano. Trata-se, de fato, de disciplinas eminentemente qualitativas, que têm por objeto casos, situações e documentos individuais, enquanto individuais, e justamente por isso alcançam resultados que têm uma margem ineliminável de casualidade; basta pensar no peso das conjeturas (o próprio termo é de origem divinatória) na medicina (...) A ciência galileana tinha uma natureza totalmente diversa, que poderia adotar o lema escolástico individuum est ineffabile, do que é individual, não se pode falar. O emprego da matemática e o método experimental, de fato, implicavam respectivamente a quantificação e a repetibilidade dos fenômenos, enquanto a perspectiva individualizante excluía por definição a segunda, e admitia a primeira apenas em funções auxiliares." 45

Isto contraria frontalmente a intenção generalizadora implícita na teoria das doenças. É interessante notar que este processo de individualização aproxima a clínica e a psicanálise, num certo sentido, aproximação esta indesejada por muitos médicos, mas também por outros tantos psicanalistas.

\section{b. Clínica e terapêutica}

Na relação doença/tratamento encontramos mais um dos paradoxos clínicos: pela teoria das doenças, uma vez que se chegue "cientificamente" ao diagnóstico, o tratamento é identificado de forma unívoca, igualmente "científica". Na prática, o médico adota uma conduta própria, na qual as evidências teóricas são filtradas pela sua experiência. Apesar do discurso generalizante, $o$ tratamento continua sendo uma instância individual, quer se pense em termos de médico (cada médico tem sua conduta) quer se pense em termos de pacientes (para cada paciente a conduta de um mesmo médico pode ser variável).

Embora certamente haja uma racionalidade no estabelecimento da terapêutica, dificilmente esta pode ser considerada "científica", ao menos nos termos do paradigma galileano onde querem colocá-la, pois falta à conduta individualizada um dos atributos básicos do experimento científico: a reprodu-

45 GINZBURG, Carlo, "Sinais: raízes de um paradigma indiciário". in Mitos, emblemas, sinais. Cia. das Letras, São Paulo, 1989 — p. 156. 
tibilidade. Não raro médicos apresentam condutas divergentes, sem que isso seja visto como sinal de má técnica.

O que é mais interessante é que estas condutas podem ser igualmente eficazes, apropriadas, nas mãos daqueles que as adotam. O que pretendo ressaltar com isso é que a "cientificidade", ao menos como desejada pelos teóricos da medicina, não é condição fundamental para o sucesso terapêutico.

Ao contrário do que o discurso dos seus ideólogos supõe, a prática médica depende em muito da habilidade individual dos seus praticantes, assim como a qualidade de um calçado, nos idos tempos da manufatura, dependia da habilidade do artesão. Não há qualquer intenção de desprestígio nesta comparação, muito pelo contrário. Quando Nélson Blank aponta para o caráter subjugador e expropriatório que o equipamento médico tem em relação à prática médica, ${ }^{46}$ esta "ameaça" existe precisamente porque se toma como objetivo último a "medicina científica". O que é expropriável é a repetição mecânica de condutas padronizadas. A habilidade é intransferível.

A maior ameaça à medicina, então, não vem tanto das práticas concorrentes, mas sim da própria dinâmica interna de "cientifização" da prática clínica.

\section{c. Clínica e magia}

A crença dos médicos na "cientificidade" da sua prática - e mais que isso, na eficácia desta "cientificidade" - é, num certo sentido, mágica, já que a forma como os conhecimentos são produzidos lhes escapa, fazendo com que esses conhecimentos sejam incorporados à sua prática de forma acrítica. Por outro lado, a "mágica" do xamã de Lévi-Strauss ${ }^{47}$ é referida a um sistema coerente de representações, partilhado com sua "paciente", o que lhe confere a "eficácia simbólica" a que o próprio título da artigo alude. Neste sentido, o da coerência do discurso, o xamã é mais científico do que nós médicos sonhamos ser.

O esforço de generalização/objetivação empreendido pela clínica se dá às custas da biologização do processo de adoecer. Isto limita as possibilidades de atuação médica ao biológico, o que impõe sérias restrições do ponto de vista da eficácia a esta prática. Por paradoxal que isto possa parecer, abandonando a busca da quimera científica talvez possamos ser científicos como nunca fomos. Ter certeza, como a clínica supõe ter, é fatal às dúvidas, matriz da investigação científica. 
Talvez falte à clínica não uma "cientificidade" incompatível com sua característica indiciária, mas ao invés disso desenvolver uma atitude científica que permita que a dúvida permeie as pétreas defesas erguidas em torno do castelo da teoria das doenças. Se, no exercício clínico, os médicos puderem desenvolver esse tipo de visão crítica, talvez aí exista espaço para um reencontro da medicina com seu objetivo presumido, aliviar sofrimentos. Se esta "desmedicalização" da medicina é possível, não há como dizer. Creio, todavia, que posso afirmar com segurança que a proposta inicial deste trabalho, com todas as suas limitações, foi cumprida.

\section{Epílogo}

Gostaria de encerrar este trabalho com a história, relatada por Lévi-Strauss, de Quesalid, o Kwakiutl que, para desmarcarar os feiticeiros, resolve estudar seus métodos... e se torna um deles. Assim se encerra o relato: “(...) A atitude do começo se modificou, pois, sensivelmente: o negativismo radical do livre pensador cedeu lugar a sentimentos mais matizados. Existem verdadeiros xamãs. E ele próprio? Ao fim da narrativa, não se sabe; mas é claro que exerce seu ofício com consciência, que é orgulhoso de seus sucessos e que defende calorosamente, contra todas as escolas rivais, a técnica da plumagem ensanguentada, da qual parece ter perdido de vista, completamente, a natureza falaciosa, e da qual tanto zombara no início." 48

Talvez na condição de feiticeiros descrentes de nossa feitiçaria possamos recuperar não só sua eficácia como a dignidade de que andamos tão necessitados... Que Asclépios, Amon e tantos outros nos protejam.

\section{RESUMO}

\section{(Ir)racionalidade Médica: os paradoxos da clínica}

O ponto de partida deste trabalho é a tentativa de examinar a prática e o saber médico nas suas articulações internas, em contraste com as análises críticas da medicina que usualmente partem de um ponto de vista externo, com uma abordagem sociológica ou econômica.

A partir deste referencial, constata-se que a suposta cientificidade da medicina não se sustenta ao analizar-se seus referenciais teóricos, em especial

48 LÉVI-STRAUSS, Claude, "O feiticeiro e sua magia". op. cit.. p. 206. 
no que diz respeito à epidemiologia, disciplina fundamental na constituição dos objetos da prática médica - as doenças - desconhecida pela maioria dos médicos. Mais ainda, categorias fundamentais do raciocínio clínico nunca são definidas, como se fossem objetos naturais, dados, o que faz com que a razão principal da busca por atenção médica, o sofrimento, seja marginalizado dentro do pensamento médico, e que o paciente seja apagado para que surja a doença.

Por fim, a partir da constatação do caráter eminentemente individualizado do exercício da medicina, o que por si só a afasta do paradigma das ciências naturais, defende-se a adoção de uma atitude científica que permita ao médico questionar as bases de sua prática e recuperar o papel do sofrimento como eixo principal do pensamento médico.

\section{ABSTRACT}

\section{Medical (ir)rationality: clinic's paradoxes}

The main concern of this study is an attempt to examine medical practice and knowledge from their "innards", contrasting with usual critical analyses that are often made from an external standpoint, not mattering wether the approach is that of social sciences or economics.

With this guideline as a starting point, it becomes evident that the supposed scientificity of medicine doesn't hold when one analyses its theoretical framework, specially into what epidemiology, a core discipline to the construction of objects for the clinical practice, is concerned. Moreover, categories that are basic to clinical reasoning remain undefined, as if they were natural objects, already existant, and this allows for the main reason for the search for medical care, suffering, to be put aside from medical thinking, and the patient to become faded away so that disease can arise therefrom.

Finally, with regard to the eminently individualized character of medical practice, which in itself departs from the natural sciences' paradigm, the adoption of a scientific atitude is advocated, so that doctors can exert a certain criticism on the basis of their practice and recover the role of suffering as the main axis of medical thinking. 


\section{RESUME}

\section{L'(Ir)rationnalité médicale: les paradoxes de la médecine clinique}

Les analyses critiques de la médecine prennent appui sur des critères qui lui sont externes, empruntés à la sociologie ou aux sciences économiques. C'est pourquoi cet article s'efforce par contraste d'examiner la pratique et le savoir médicaux à partir de leurs propres articulations internes.

Cette prise de position amène l'auteur à constater que le soidisant caractère scientifique de la médecine n'a aucune base. Il observe en effet que la plupart des médecins ignorent ses réferentiels théoriques et notamment l'épidémiologie qui est une discipline fondamentale à la constitution de l'objet de la pratique médicale: les maladies. Mieux encore: les catégories fondamentales du raisonnement médical ne sont en fait jamais définies commes s'il s'agissait là d'objets naturels, de données factuelles. En conséquence, la pensée médicale a tendance à marginaliser ce qui constitue pourtant la raison principale de ceux qui se mettent en quète d'un médecin: la souffrance. Elle efface le patient au profit de la maladie.

L'auteur constate enfin que la médecine est une activité extrèmement individualisée, ce qui en soi suffit à la rendre distante du paradygme des sciences naturelles. Mais il n'en préconise pas moins l'adoption par les médecins d'une attitude scientifique, capable de les amener à la soufrance le rôle d'axe principal de la pensée médicale. 


\title{
PHYSIS
}

\section{A PUBLIC HEALTH JOURNAL}

\author{
Issue $n^{\circ} 1$ : Sexuality and AIDS
}

A Disease within a Public Space: AIDS in six French newspapers
CladTINE HeRZLICH
JANINE PIERRET

Innocence and Vice: Du Côté de Chez Proust

JuRANIIIR Freire COSTA

Femaleness - The Controversy of the Obvious

JACQUELINE MUNIZ

Sexuality and Reproduction

MARIA ANDRÉa LOYOLA

From Human Blood to Politics: the Impact of AIDS in Brazil Luiz A. de Castro Santos

Claudia Moraes

Vera Schattan P. Coelho

Homosexuality, Bisexuality, and HIV/AIDS in Brazil:

An Annotated Bibliography of Social Science Publications

CARMEn Dora GuIMarães

VERIANo TERTo Jr.

RICHARD GUY PARKER

The State, Social Movements, and Reforms in Latin America: A Reflection on the Contemporary Crisis

CRISTINA Possas

Medical (ir)rationality: clinic's paradoxes

KenNeth Rochel de CAMargo Jr. 
230 PHYSIS - Revista de Saúde Coletiva

ARTIGOS A SEREM PUBLICADOS NOS PRÓXIMOS NÚMEROS:

1. Objeto da Epidemiologia e Nós

José RICARIOO DE C. M. Ayres

2. Construção Cientifica e Inovação Teórica: Um Desafio para a Epidemiologia

Dina CZEREsnia

3. Desinstitucionalização da Assistência Psiquiátrica: uma Perspectiva Crítica

Maldricio Lougon

4. Os Encargos da Morte

Claudine Herzlich

5. O Instituto Pasteur de São Paulo: uma Contribuição a Historia das Instituições Biomédicas no Brasil Luz ANTONIO TEIXEIRA 